\title{
Analytical Review on the Stakeholders Perceptions about IPv6 Readiness and their Implications to the Omani Higher Education Institutions
}

\author{
Al Musawi, Ali*, Shubair A., Samih S., Abraham V and Alghatrifi, Issa \\ Sultan Qaboos University, POBox 32 PC 123 Al Khodh Oman; the Higher College of Technology, IT Department, Al-Kuwair, Oman; IT \\ Department, Technical College, Nizwa, Oman
}

Received 05 June 2018, Accepted 08 Aug 2018, Available online 10 Aug 2018, Vol.8, No.4 (July/Aug 2018)

\begin{abstract}
This paper describes the first stage of an internal grant provided by the Sultan Qaboos University to conduct a research project exploring the actual readiness of Higher Education Institutions (HEIs) to adopt a national migration plan to IPv6. Document analysis was used to derive necessary data on steps taken by the Omani concerned authorities to pave the way for the migration process. It was found that the Telecommunication Regulatory Authority (TRA) established IPv6 project 10 years ago. It has issued a circular on 'The National Migration Plan for Government Sector' informing all administrative units of the Sultanate about the preparation of the national plan to prepare detailed transition plans to migrate to IPv6 by the end of year 2020. Data on these agencies' (specifically higher education institutions) response is scarce and unclear. From the literature review, it was found that there is no research dedicated for the Omani HEIs IPv6 readiness. Therefore, next stage of the research project will investigate the actual readiness of HEIs as perceived by their stakeholders including ICT personnel, technical administrators, and senior administrators to implement the next generation of Internet protocol in these institutions.
\end{abstract}

Keywords: IPv6, Oman, Reediness, Higher education, National migration plans

\section{Introduction}

Along with the new trends of markets for internetworking of physical devices, vehicles, buildings, etc. and the widespread use of mobile devices, the demand for addresses to identify devices connected and allow them to communicate is increasing dramatically. The Internet Protocol (IP) addresses are the type of addresses that the devices connected to the internet use to exchange data between each other. The version 4 of IP (IPv4) is currently used as the main addressing scheme. IPv4 addresses are 32 bits in length that uniquely identify a device on IP network. They are typically notated in a format knows as dotted decimal, where the 32 bits are notated using four decimal numbers separated by periods, for example 192.168.1.44. Table 1 shows the main differences between IPv4 and its successor IPv6.

As shown in Table 1, IPv4 has a fixed number of addresses approximately $2^{32}=4.3$ billion (Coffeen, 2014). According to the prediction of the Cisco Internet Business Solutions Groups (Cisco IBSG), the Cisco's global consultancy, the connected devices to the

*Corresponding author's ORCID ID: 0000-0002-6893-3216 DOI: https://doi.org/10.14741/ijcet/v.8.4.22
Internet by 2020 will 50 billion devices (Ansari, Sedky, Sharma, \& Tyagi, 2015). On February 3, 2011, the Internet Assigned Numbers Authority (IANA) allocated the last unallocated blocks of IPv4 address space to the Regional Internet Registries (RIRs), who in turn allocate blocks of addresses to institutions and Internet Service Providers (ISPs). As a result, the Internet is on its way to a fundamentally transition motivated by the exhaustion of IPv4 address space. "As the Internet becomes the true global medium, the innovations and persistent efforts of individuals are needed to build a network that is capable of supporting a variety of services in a robust manner" (Ladid, 2000). The theme of transition is to move to new addressing scheme having 128 bits so called IPv6 (Graziani, 2012). IPv6 shall provide more than one unique IPv6 address for every connected device regardless of the gadgets or the users exist in the long future (Ali, 2012). "The addressing issue gets a lot of attention, but it is only one of many important issues that IPv6 designers have tackled. Other capabilities have also been developed in direct response to critical business requirements for scalable network architectures, improved security and data integrity, integrated quality-of-service, and automatic configuration" (Ladid, 2000). 
Table 1 IPv4/IPv6 comparison

\begin{tabular}{|c|c|c|}
\hline & IPv4 & IPv6 \\
\hline Invention & 1981 & 1999 \\
\hline Address length & $\begin{array}{l}4 \text { bytes } \\
32 \text { bits }\end{array}$ & $\begin{array}{l}16 \text { bytes } \\
128 \text { bits }\end{array}$ \\
\hline No. of addresses & $\begin{array}{c}\qquad 2^{32} \approx 4.2 \text { billion } \\
\text { (Less than a single IP address per person on the } \\
\text { planet) }\end{array}$ & $2^{128} \approx 340$ trillion trillion trillion \\
\hline Address format & $\begin{array}{c}\text { Dotted decimal notation: } \\
192.168 .10 .1\end{array}$ & $\begin{array}{c}\text { Hexadecimal notation: } \\
\text { 2001:0db8:85a3:0000:0000:8a2e:0370:7334 }\end{array}$ \\
\hline Packet size & $\begin{array}{c}576 \text { bytes required } \\
\text { fragmentation optional }\end{array}$ & $\begin{array}{l}1280 \text { bytes required } \\
\text { no fragmentation }\end{array}$ \\
\hline \multirow[t]{2}{*}{ Packet header } & includes options up to 40 byte & extension headers used for optional data \\
\hline & include checksum & does not include checksum \\
\hline $\begin{array}{c}\text { Address } \\
\text { configuration }\end{array}$ & $\begin{array}{c}\text { Manual or via Dynamic Host Configuration } \\
\text { Protocol (DHCP) }\end{array}$ & $\begin{array}{c}\text { Manual, via Stateless address } \\
\text { autoconfiguration (SLAAC), or via DHCPv6 }\end{array}$ \\
\hline Security features & $\begin{array}{l}\text { Security is dependent on applications, and the } \\
\text { Internet Protocol Security (IPSec) is optional }\end{array}$ & IPSec is built into the IPv6 protocol \\
\hline $\begin{array}{c}\text { Interoperability \& } \\
\text { mobility }\end{array}$ & Very constrained interoperability and mobility & $\begin{array}{c}\text { Designed to provide interoperability and } \\
\text { mobility capabilities }\end{array}$ \\
\hline
\end{tabular}

Table 2: Governments IPv6 Deployment Roadmaps*

\begin{tabular}{|c|c|c|c|}
\hline Governments & $\begin{array}{c}\text { IT Policy -- IPv6 Roadmap -- } \\
\text { Adoption Year }\end{array}$ & Milestones 1 & Milestones 2 \\
\hline United States & $\begin{array}{c}\text { IPv6 Strategy } \quad-\text { Year } 2009 \\
\text { Refreshed } \quad-\text { Year } 2012\end{array}$ & $\begin{array}{l}\text { Public web sites - } 9.2012 \\
\text { Result: } 35 \% \text { - May } 2013\end{array}$ & $\begin{array}{l}\text { Complete transition to } \\
\text { IPv6 (dual stack) by } \\
\text { December } 2017\end{array}$ \\
\hline Australia & $\begin{array}{c}\text { AGIMO IPv6 Strategy - Year 2008 } \\
\text { Stage 1: Preparation (2008-2009) } \\
\text { Stage 2: Transition }(2010-2011) \\
\text { Stage 3: Implementation }(2012- \\
\text { 2012) }\end{array}$ & $\begin{array}{c}\text { Tasks: } \\
\text { Review Procurement } \\
\text { Policy. } \\
\text { Stocktake of Equipment. } \\
\text { Stocktake of Applications. }\end{array}$ & $\begin{array}{l}\text { Government Transition to } \\
\text { IPv6: Stage 2: Transition: } \\
\text { Jan 2010 - Dec } 2011 \\
\text { Implementation: Jan } 2012 \\
\text { - Dec 2012 }\end{array}$ \\
\hline Canada & $\begin{array}{l}\text { IPv6 adoption strategy - Year } \\
2012\end{array}$ & $\begin{array}{c}\text { Enabling Phase - Sep } \\
2013 \\
\text { Deployment Phase - } 2015\end{array}$ & $\begin{array}{c}\text { Completion Phase - } \\
\text { 201X? }\end{array}$ \\
\hline India & $\begin{array}{lll}\text { IPv6 Policy } & -- & \text { Year } 2010 \\
\text { Updated } & -- & \text { Year } 2013 \\
\end{array}$ & $\begin{array}{l}\text { Public web sites - } \\
\text { 1.1.2015 }\end{array}$ & $\begin{array}{l}\text { Complete transition to } \\
\text { IPv6 (dual stack) by } \\
\text { December } 2017\end{array}$ \\
\hline China & $\begin{array}{lll}\text { CNGI } & -- & \text { Year } 2006 \\
\text { NDRC } & \text {-- } & \text { Year } 2012 \\
\end{array}$ & 8M IPv6 users by 2013 & $\begin{array}{l}\text { 25M IPv6 users by 2014- } \\
5\end{array}$ \\
\hline European Commission & $\begin{array}{c}\text { i2010 } \\
\text { EU IPv6 Task Force Year } 2001 \\
\text { IPv6 Communication 2004 } \\
\text { IPv6 Communication 2008 }\end{array}$ & $\begin{array}{c}\text { 25\% IPv6 users by } 2010 \\
\text { Result: } 1 \%\end{array}$ & \\
\hline Indonesia & $\begin{array}{l}\text { IPv6 Task Force -- Year } 2005 \\
\text { Phase 1: } 2006 \text { Dissemination, } \\
\text { Research }\end{array}$ & $\begin{array}{c}\text { Phase 2: } 2007 \\
\text { Development } \\
\text { of infrastructure and } \\
\text { Content } \\
\end{array}$ & $\begin{array}{c}\text { Phase 3: } 2008- \\
\text { Development of } \\
\text { Applications and Transition } \\
\text { Process } \\
\end{array}$ \\
\hline Taiwan, R. of China & E-Taiwan Strategy--Year 2002 & $\begin{array}{l}\text { Phase 1: } 03-05 \\
\text { Promotional } \\
\text { strategy }\end{array}$ & $\begin{array}{c}\text { Phase } 205-07 \\
\text { Implementation strategy }\end{array}$ \\
\hline South Korea & IT839 Strategy -- Year 2004 & ISP Readiness & IPv6 service \\
\hline Japan & U-Japan -- Year 2001 & ISP readiness & IPv6 service \\
\hline
\end{tabular}

$$
\text { * Source: Ladid (2016) }
$$

Due to the vastness of the Internet and the complexity of transitioning the entire Internet to IPv6, it has been realized from the beginning that the transition would be a long-term process and it involves significant effort and investments in terms of national human resources and national communication infrastructure. Several network operators and service providers have migrated their networks to IPv6 networks. Similarly, several countries throughout the world (see Table 2 below) have already planned for a time-frame migration to their national communication infrastructure into IPv6 operable communication infrastructure with the formation of roadmaps and policies (Dawadi, Shakya, \& Khanal, 2016; Dell, 2012; Main, Zakaria, \& Yusof, 2015).

There were four basic issues faced in the technology implementation; namely, security issues, addressing issues, error detection issues and Wireless Sensor Network issues (Meena \& Bundele, 2015). Threats resulting from these implementation issues require updated training/education and enhanced countermeasures. In addition, traditional monitoring approaches are usually not appropriate for IPv6 traffic and therefore, new techniques, effective algorithms 
and data structures need to be deployed (Grégr, Petr Matoušek, Podermański, \& Švéda, 2011). In addition to traditional network services, educational infrastructures must enable specialized resources such as registration, billing, and online systems on devices that will increasingly run IPv6; applications must be available, fast and secure and video surveillance are vital too. Further, literature argues that universities and research institutions should adopt an IPv6 strategy with at least three facets: acquisition policies that promote increasing readiness; develop knowledge and experience through experimentation and pilot projects; and seek opportunities to work with organizations to facilitate the general adoption of IPv6 (Martin \& Heyer, 2004). HEIs have to lead the way with new technologies, as this is one of their social responsibilities.
Efforts in the Middle East are being made to strategize for IPv6 migration. These efforts are summarized in Table 3 below. Sultanate of Oman has gained significant momentum in ICT development; however, proper policy and regulatory framework is needed to cope with IPv6 technology migration to make the HEIs synchronize with the world's technologies and to fulfill the current market's demands. However, efforts are scarce in IPv6 implementation. For example, the Telecommunication Regulatory Authority (TRA) provides a website and one-time training. The national organizations including TRA, ISPs, ITA, universities, government organizations, non-governmental organizations, etc. that are not well prepared for IPv6 may find themselves at low levels of IPv6 readiness and could constitute a significant problem for the higher education and ICT industry.

Table 3: National Regulators IPv6 Deployment Roadmaps*

\begin{tabular}{|c|c|c|c|}
\hline $\begin{array}{c}\text { National Regulators IPv6 } \\
\text { Deployment Roadmaps } \\
\text { Regulator }\end{array}$ & $\begin{array}{c}\text { IT Policy -- IPv6 Roadmap -- } \\
\text { Adoption Year }\end{array}$ & Milestones & Results \\
\hline & IPv6 Strategy -- Year 2008 & 3 Studies: & 14 ASNs support IPv6 \\
Saudi CITC & IPv6 Readiness Assessment & Infrastructure Track \\
IPv6 Countries Benchmark & Awareness Track have IPv6 traffic \\
IPv6 International bodies \& & Organizations & Transition Process & OmanTel Testing IPv6 \\
\hline Oman TRA & Oman IPv6 Strategy--Year 2010 & IPv6.om Web Site & Strategy published in 2013 \\
\hline Morocco ANRT & IPv6 Study -- Year 2012 & ISP Readiness work & * Source: Ladid (2016)
\end{tabular}

This paper describes the first stage of an internal grant provided by the Sultan Qaboos University (SQU) to conduct a research project exploring the actual readiness of HEIs to adopt the above national plan to migrate to IPv6.

\section{Research Significance}

Practically, there is no research dedicated for the Sultanate of Oman HEIs IPv6 readiness. It is difficult for universities and ISPs to achieve a well-managed IPv6 transition without concrete understanding of the IPv6 readiness. On the other hand, there has been no empirical research with focus on actual knowledge and readiness of network engineers, network administrators, security personnel, and IT supporters who will be directly or indirectly involved in IPv6 implementation.

The researchers proposed a research project in an attempt to fill this research gap by investigating the actual readiness of HEIs as perceived by their stakeholders including ICT personnel, technical administrators, and senior administrators to implement the next generation of Internet protocol in these institutions.

\section{Research Objectives}

The main aim of this research is to provide a better understanding about the readiness of HEIs and ICT personnel for IPv6 migration to assist the process of preparation towards IPv6 adoption in these institutions.

\section{Research Questions}

1) What are the factors isolated from the literature to improve the readiness of the Omani HEIs for IPv6 migration?

2) What effect do the governmental IPv6 migration plan has on the Omani HEIs?

3) What implications do the findings so far suggest to inform the research process?

\section{Method}

Analytical and document review was conducted as follows:

1) IPv6 in the global HEIs context was studied.

2) Documents concerning the Omani context both on the national and HEIs levels were analyzed.

However, qualitative research method will be subsequently employed in order to triangulate the findings. Those are explained below in the 'Conclusions and Next Steps' section.

For the purpose of this stage of research project, the TRA and other institutional documents were consulted, field visit to TRA took place and a meeting was 
conducted with the stakeholders to collect the required documents.

\section{Analytical Review Findings}

\section{- $\quad$ Global HEIs Status}

IPv6 is developed to meet the increasing needs of internet and, in the case of higher education institutions (HEIs); these institutions are the main focus to conduct IPv6 readiness research (Southworth, 2016). Southworth (2016) has surveyed 1,000 American colleges and universities to determine the rate of IPv6 readiness. Institutional factors (e.g. implementation, infrastructure, policy and training) were analyzed and found to be related to IPv6 readiness and effectiveness. In Texas, LEARN, is a consortium of 38 public and private institutions of higher education, community colleges, K-12 public schools, and the National Weather Service provides high speed optical network services to support research, education, healthcare, and public service missions. It uses dual stack IPv4 and IPv6 on all production backbone networks. The consortium educates its members through working groups and workshops and relies on continuous education and awareness campaigns to promote the migration process (Hicks, 2012).

In Europe, "governments from various countries are responding differently to the imminent exhaustion of the IPv4 address space. The more economically advanced and export oriented countries have set clear objectives with predetermined and measurable deadlines for implementing IPv6 into public, state and private communication networks. Despite the decline in economic growth, governments in some countries did not lower but actually increased the budget for investments into the ICT infrastructure that will be IPv6 based." (Kunk, et al. 2012).

In Malaysia, Abulkasim and Ahmad (2015) found that IPv6 network has not been widely used among the institutions of higher learning in Malaysia. The study provides systematic performance testing of IPv6 guidelines in the aspect of network connections. It seems that HEIs will need sufficient time for planning the IPv6 transition, enough fund to replace old technologies along with cross-institutional collaborative research and shared access to data repositories (Almes, Anderson, Mundrane, \& Polichar, 2013). In Norway, only $30 \%$ of HEIs has deployed IPv6 with only $20 \%$ of their clients on IPv6. This is because they suffer from lack of services and miss IPv6 support in wireless controllers. The national strategy calls to make IPv6 available as well as the information about its purpose, increase the knowledge, remove any obstacle and provide institutional workshops and practical implementation consultancy (Boe, 2012). In Africa, many initiatives, many reasons account for lack of IPv6 adoption in higher education. These are related to lack of native IPv6 Internet access, services available, and networking hardware components and infrastructures. Dandjinou (2014) proposed a policy to adopt IPv6 by African higher Education institutions and ways to follow for efficient migration in the Africa region.

\section{- IPv6 in the Omani context}

A Circular (No. 1/2018) was issued by the TRA on 'The National Migration Plan for Government Sector' informing all administrative units of the Sultanate about the preparation of the national plan. It also request these agencies to comply and abide by what came in this plan according to the above-mentioned time stages, in order to facilitate the transition to the Sixth version of the Internet Protocol addresses efficiently. The plan lists the obligations actions to be enforced by the government authorities as follows (TRA, 2018a):

1) The preparation of detailed transition plan to fully move to the Internet Protocol Version 6 addresses (IPv6) (dual stack) by December 2020, depending on the complexity of the network and life expectancy of equipment and techniques.

2) The transition plan would be ready by December 2018.

3) That all new services based on the Internet Protocol (such as cloud computing and data centers, etc.) which are provided to/from governmental bodies supporting the $6^{\text {th }}$ version of the internet protocol addresses (IPv6), with immediate effect from the date of issuance of this circular

4) That all new services/applications/systems/email which provide services to the public, support the sixth version of the internet protocol addresses (IPv6), with immediate effect from the date of issuance of this circular.

5) That all current services/application/system/ email messages that provide services to the public, support the sixth version of the internet protocol addresses (IPv6) before the fourth quarter of the year 2019 .

6) All governmental authorities to stop the purchase of equipment and systems incompatible with Version 6 of IPv6 addresses, with immediate effect from the date of issuance of this circular.

\section{- The Omani National Migration Plan for Government Sector}

It seems that TRA was working on the IPv6 long before 2018. In fact, Table 4 below shows that the National Plan preparation went back 10 years ago since TRA established IPv6 project. In addition, TRA plans to conduct an 'IPv6 National Migration Initiative Survey'. The instrument was constructed and to be implemented soon (see Appendix 1). 
Table 4: Main stages and sequence of the National Plan*

\begin{tabular}{|c|c|}
\hline The main components of the Plan & Timeline \\
\hline \multicolumn{2}{|l|}{ Stage 1: Context Analysis and Building Awareness } \\
\hline $\begin{array}{l}\text { Started communications with operators regarding IPv6 (TRA always communicate with operators } \\
\text { on this regard and follow-up with them). }\end{array}$ & $10 / 06 / 2008$ \\
\hline Lunching of ipv6 website & $18 / 8 / 2010$ \\
\hline IPv6 leaflet & $27 / 9 / 2010$ \\
\hline \multicolumn{2}{|l|}{ Stage 2: Design and Development of Procedures } \\
\hline TRA testing the implementation of IPv6 with Omantel & $24 / 12 / 2012$ \\
\hline $\begin{array}{l}\text { The Type approval department has to play an essential role in promoting the use of devises that is } \\
\text { IPv6 enabled during COMEX or other exhibitions. }\end{array}$ & In COMEX 2013 \\
\hline TRA become the one of the LIR and have received the first IPV6 Allocation for network assignment & $28 / 5 / 2013$ \\
\hline TRA has become a member of RIPE NCC & $29 / 7 / 2013$ \\
\hline \multicolumn{2}{|l|}{ Stage 3: Adoption and Implementation } \\
\hline IPv6 adoption in Oman (Task force) & $26 / 1 / 2017$ \\
\hline The Domain Names Registry system became IPv6 & November 2017 \\
\hline IPv6 workshop in TRA presents by RIPE & $16-20 / 4 / 2017$ \\
\hline The registry website www.registry.om became IPv6 & $8 / 2 / 2018$ \\
\hline \multicolumn{2}{|l|}{ Stage 4: Nation-wide dissemination } \\
\hline IPv6 schema training & March 2018 \\
\hline Directives to the Licensees & $8 / 4 / 2018$ \\
\hline circular to many government entities and some companies regarding the migration to IPv6 & $9 / 4 / 2018$ \\
\hline directives to the Equipment's Dealers/importers & $25 / 4 / 2018$ \\
\hline $\begin{array}{l}\text { From } 31 \text { June 2018, all devices must support IPv6 and the devices that support only IPv4 will not } \\
\text { accepted. }\end{array}$ & May 2018 \\
\hline Announcement regarding ipv6 through newspaper, twitter, TRA website & $16 / 5 / 2018$ \\
\hline \multicolumn{2}{|l|}{ Stage 5: Evaluation and Feedback } \\
\hline Conduct IPv6 National Migration Initiative Survey' & $2018-2020$ \\
\hline
\end{tabular}

* Source: TRA (2018b)

\section{Conclusions}

It seems that the factors isolated from the literature to improve the readiness of the Omani HEIs for IPv6 migration can be summarized in providing the stakeholders with sufficient time for planning, financial resources, assuring the applications compatibility and security. Planning the transition also requires structural preparedness, developing a technical plan, developing a security Plan, and developing a rollout plan (Almes, et al. 2013).

Although the Sultanate gives due importance to the transition process, data on the governmental agencies response is scarce and unclear. More importantly, HEIs' (specifically those in the private sector) response seems to be even vaguer as they were not mainly targeted at the initial stages of the project. It can be therefore concluded the governmental IPv6 migration plan has minimal effect on the Omani HEIs. This result gives importance to continue the research project with

\section{Future Implications to Research Project}

From what has been found above, the research team needs to refocus the objectives of the project. Specifically the research should try to assess the IPv6 readiness in terms of infrastructure, the ICT personnel perceptions about the deployment of IPv6 in terms of
IPv6 knowledge and the IPv6 readiness in HEIs in terms of research and teaching the IPv6 technology. Further, the research questions will be accordingly refined (see Southworth, 2016 and Almes, et al. 2013, ) to investigate the extent to which the status provides for IPv6 readiness in terms of: awareness, current environment, planning, deployment and infrastructure, policy frameworks, training, research, human resources, and courses provision as perceived by Omani HEIs faculty, administrators and ICT personnel.

The concerns/problems of IPv6 as perceived by the stakeholders. Ultimately, the research project outcome will be the best policy model to provide for IPv6 in the Omani HEIs. The research participants should include all Omani HEIs stakeholders in ICT fields. Random sampling will be applied with a ratio of $15 \%$ of the faculty, administrators and ICT personnel Methodologically, a questionnaire will be designed, reviewed, and distributed to survey the stakeholders perceptions followed by focus group interviews to investigate issues isolated from the questionnaire analysis in more details. The questionnaire will benefit from 'IPv6 National Migration Initiative Survey' (see Appendix 1). Table 5 below shows the tasks and timeline of the research project. The work team will conduct training courses and issue practical guide of the HEIs migration policy to IPv6. 
Table 5: Research project's Timeline

\begin{tabular}{|c|c|c|c|c|c|c|c|c|}
\hline \multirow{2}{*}{$\begin{array}{c}\text { Task/ } \\
\text { Time }\end{array}$} & \multicolumn{9}{|c|}{2018} & \multicolumn{3}{c|}{2019} \\
\hline & $\begin{array}{c}\text { Design/ } \\
\text { Review }\end{array}$ & Development & Implantation & $\begin{array}{c}\text { Analysis/ } \\
\text { Writing }\end{array}$ & Design & $\begin{array}{c}\text { Develop } \\
\text { ment }\end{array}$ & $\begin{array}{c}\text { Implantation } \\
\text { Analysis/ } \\
\text { Writing }\end{array}$ \\
\hline Literature Review & & & & & & & & \\
\hline Questionnaire & & & & & & & & \\
\hline Interviews & & & & & & & & \\
\hline Reports & & & & & & & & \\
\hline Training courses & & & & & & & & \\
\hline Practical Guide & & & & & & & & \\
\hline
\end{tabular}

We express our gratitude to the SQU for the generous grant awarded to us. Further, we appreciate the TRA stakeholders' cooperation in meeting the research team and providing the required documents and resources. Such institutional efforts make this research project possible.

\section{References}

Abulkasim, A. F. S., \& Ahmad, A. A. (2015). IPV6 Deployment Status for Higher Education Institutions' Website of Ministry of Education Malaysia. International Journal of Current Engineering and Technology, 5(2), 1060-1067.

Ali, A. N. A. (2012). Comparison study between IPV4 \& IPV6. International Journal of Computer Science Issues, 9(3), 314-317.

Almes, G., Anderson, C., Mundrane, M., \& Polichar, V. (2013). Transitioning to IPv6. In ECAR (Ed.), ECAR reports: EDUCAUSE.

Ansari, A. N., Sedky, M., Sharma, N., \& Tyagi, A. (2015). An Internet of things approach for motion detection using Raspberry Pi. Paper presented at the Intelligent Computing and Internet of Things (ICIT), 2014 International Conference on

Boe, G. (2012). IPv6 in higher education in Norway, The last IPv6 workshop Helsinki 2012-10-04, UNINETT.

Coffeen, T. (2014). IPv6 Address Planning: Designing an Address Plan for the Future: " O'Reilly Media, Inc.".

Dandjinou, P. (2014). Preparing African Higher Educations Institutions for IPv6 Networking, Paper presented to the Association of African Universities, Accra-North, GH, Available: https:// idl-bnc-idrc.dspacedirect.org/handle/ 10625/53453

Dawadi, B. R., Shakya, S., \& Khanal, A. R. (2016). Government Roadmap for IPv4 to IPv6 Network Migration: A Case of Nepal. Journal of the Institute of Engineering, 11(1), 67-78.

Dell, P. (2012). Australian IPv6 readiness: Results of a national survey. Journal of Research and Practice in Information Technology, 44(1), 3.
Graziani, R. (2012). IPv6 fundamentals: a straightforward approach to understanding IPv6: Pearson Education.

Grégr, M., Petr Matoušek, Podermański, T., \& Švéda, M. (2011). Practical IPv6 Monitoring on Campus: Best Practice Document: TERENA.

Hicks, B. (2012). IPv6 within Texas Research and Education, Paper presentation, Lonestar Education And Research Network (LEARN), Available: http://www.tx-learn.net/

Kunc, U., Pepelnjak, I., Sterle, J., Istenič, M., Kobal, A., Lisec, S., Maennel, and O., Žorž, J. (2012). Transition to IPv6, Ministry of Higher Education, Science and Technology, Slovenia.

Ladid, L. (2000). IPv6-The new-generation Internet Ericsson Review(1), 6-13.

Ladid, L. (2016). IPv6 based Internet, Paper presented at the $3^{\text {rd }}$ Middle East College International Conference, March 15-16 2016, Muscat, Oman.

Main, A., Zakaria, N. A., \& Yusof, R. (2015). Organisation Readiness Factors Towards IPv6 Migration: Expert Review. Procedia-Social and Behavioral Sciences, 195, 1882-1889.

Martin, D. H., \& Heyer, A. B. (2004). Anyone for IPv6? Paper presented at the Conference of Information Technology in Tertiary Education (CITTE 2004), University of Cape Town.

Meena, R. C., \& Bundele, M. (2015). A Review on Implementation Issues in IPv6 Network Technology. International Journal of Engineering Research and General Science, 3(6), 800-809.

Southworth, J. B. (2016). An empirical analysis of the relationship between IPv6 readiness, IPv6 enablement, and IPv6 effectiveness at colleges and universities in the United States. (Ph.D.), Indiana State University. (10106058)

TRA- Telecommunication Regularatory Authority (2018a). The National Migration Plan for Government Sector, TRA official Resolution (1/2018), Muscat, Oman.

TRA- Telecommunication Regularatory Authority (2018b). Sequence of event since TRA established IPv6 project, TRA electronic document, Muscat, Oman. 